\title{
Longevity, food consumption, and foraging performance of Apis cerana and Apis mellifera in mixed colonies
}

\author{
Chuang Zhang ${ }^{1}$, Subas PoKhrel ${ }^{1,2}$, Zhenhong $\mathrm{WU}^{1}$, Xiaoqing MiAO ${ }^{1}$, \\ Zachary Y. $\mathrm{HUANG}^{3}$, Wenchao YANG ${ }^{1}$ \\ ${ }^{1}$ College of Bee Science, Fujian Agriculture and Forestry University, Fuzhou, Fujian 350002, People's Republic of China \\ ${ }^{2}$ Oxfam in Nepal, Jawalakhel-20, Lalitpur 44600, Nepal \\ ${ }^{3}$ Department of Entomology, Michigan State University, East Lansing, MI 48912, USA
}

Received 10 July 2018 - Revised 24 November 2018 - Accepted 10 December 2018

\begin{abstract}
Apis cerana is an endemic species of honey bee in Asia. A. cerana is believed to have better adaptation to scattered nectar sources than Apis mellifera, which implies that honey can be harvested from A. cerana colonies, but $A$. mellifera will starve at the same location. We hypothesize that there are differences in foraging performance, worker longevity, and daily sugar consumption between A. cerana and A. mellifera workers. These parameters in both species were determined. A. cerana had longer longevity than A. mellifera if longevity was measured in caged bees without pollen or in mixed species colonies with A. mellifera queens, but A. mellifera had much longer longevity when measured inside cages provided with pollen. A. cerana also had more foraging trips and higher proportion of foragers than A. mellifera in mixed colonies. The daily sugar consumption of A. cerana workers was $32 \%$ of that of A. mellifera, perhaps mainly due to the smaller biomass of A. cerana workers. In addition, A. cerana workers showed significantly lower variance in daily sugar consumption. In conclusion, A. cerana has more foraging trips, higher forager proportion, less sugar consumption, and longer survival than those of $A$. mellifera, when measured inside the same colonies. These differences might explain why during a dearth or in scattered resource areas, A. cerana can store or produce more honey than A. mellifera.
\end{abstract}

\section{Apis cerana / Apis mellifera / sugar consumption / foraging / survival}

\section{INTRODUCTION}

Apis cerana (Ac) and Apis mellifera (Am) are two main species of honey bees cultured in China. Both of them play important roles on pollination for many crops (Liu et al. 2016). Ac is distributed across temperate and tropical Asia (Hepburn and Radloff, 2011). In China, there are about six

Electronic supplementary material The online version of this article (https://doi.org/10.1007/s13592-018-0626-7) contains supplementary material, which is available to authorized users.

Corresponding author: Z. Huang, bees@msu.eduY.

Huang, bees@msu.edu;

W. Yang, beesyang@gmail.com

Chuang Zhang and Subas Pokhrel contributed equally to this study and share the first authorship.

Manuscript editor: edric Alaux million colonies of Am and three million colonies of Ac (FAO 2016; Ma and Huang 1993).

Ac is believed to have better adaptation to scattered nectar sources than Am (Liu 1964; Yang 2005), although this is mostly based on anecdotal observations. Ac colonies produced $10-15 \mathrm{~kg}$ of honey during the winter of $1963 / 64$, but during the same time, each Am colony had to be fed with $5 \mathrm{~kg}$ sugar (Liu 1964). These differences could be due to Ac's ability to forage at lower temperatures (Tan et al. 2012a). Ac in China routinely forages on Eurya spp. (Theaceae) and produces honey from these plants, but Am rarely produces honey from them (Yang 2005). Comparative honey production data is lacking between the two species at the same location.

Ac could produce more honey in resource scarce areas, perhaps due to the following traits. 
Besides foraging at lower temperatures, in summer, Ac workers also start foraging earlier in the morning and stop foraging later in the evening, which results in about $1 \mathrm{~h}$ more foraging duration than Am (Gupta et al. 1984; Partap et al. 2000; Chandel et al. 2000). Ac also has a better learning and memory performance when presented with color and grating patterns (Qin et al. 2012).

However, there are also foraging traits that would allow Am to outperform Ac. Am has better learning ability than Ac during odor acquisition phase (Wang and Tan 2014). Am has a longer maximum foraging distance (over $10 \mathrm{~km}$ ) (Beekman and Ratnieks 2000), compared to Ac's $1.5 \mathrm{~km}$ to $2.5 \mathrm{~km}$ (Koetz 2013). Am foragers are more sensitive to sucrose than Ac, allowing them to forage on a larger set of plant sources due to their lower threshold (Yang et al. 2013). However, the same study determined that sugar concentrations of nectar foraged by them are not significantly different, when nectar resources are scarce.

We are interested to determine if there are other factors that would allow Ac to outperform Am when resources are scarce. For example, whether Ac workers consume less sugar or have longer longevity. In this study, we determined survival of both species under different laboratory conditions and also measured their daily sugar consumption. Furthermore, we also measured worker survival and foraging traits of both species in mixed species colonies.

\section{MATERIALS AND METHODS}

\subsection{Honey bee colonies and newly emerged workers}

Three healthy colonies from each species (Am and Ac) were selected from the apiary of Apitherapy Institute, Fujian Agriculture and Forestry University, Fuzhou, China $\left(26^{\circ} 5^{\prime} 16^{\prime \prime} \mathrm{N}\right.$, $119^{\circ} 14^{\prime} 6^{\prime \prime}$ E) from April 2016 to June 2016. The ambient temperatures ranged from 13.3 (night) to $38.9^{\circ} \mathrm{C}$ (day).

Frames containing brood near emergence were selected from each colony. Those brood frames were kept in plastic cages separately and incubated at $34.5{ }^{\circ} \mathrm{C}$ and $75 \% \mathrm{RH}$ for $24 \mathrm{~h}$. These bees that emerged during the last $0-24 \mathrm{~h}$ (designated as day 0 ) were used for experiments.

\subsection{Lab study: worker longevity with sugar only and sugar consumption}

Sucrose syrup was prepared by mixing sucrose (Sinopharm, China) with water purified by reverse osmosis (RO) in the ratio of 2:1 then evenly heated to $100{ }^{\circ} \mathrm{C}$ to evaporate water and obtain a high concentration syrup. Then, the sucrose syrup was cooled to room temperature to become solidified.

Day 0 bees ( 50 bees/colony) from each colony were selected separately and put in cages $(90 \times$ $80 \times 110 \mathrm{~mm}$ ) maintained at $34.5{ }^{\circ} \mathrm{C}$ and $50 \%$ $\mathrm{RH}$. These cages were constructed with wood and a movable Plexiglas door, which had small holes drilled for ventilation. Additionally, each cage was equipped with two feeding holes on the top to insert feeders. RO water was provided in inverted $15 \mathrm{~mL}$ glass bottles with plastic cap (with three holes drilled). Solidified sucrose was provided in a plastic cap $10 \mathrm{~mm} \times 30 \mathrm{~mm}$ (height $\mathrm{x}$ inner diameter), which was hung with a wire in the cage. Both water and solidified sucrose were replaced daily. A paper towel was kept on the bottom of the cage to facilitate removal of dead bees and was changed daily. The mortality of bees in each cage was checked and recorded daily until experiments were terminated.

The amount of sucrose consumed by workers of both species was determined daily. Solidified sucrose was weighted with a precision electronic balance (Ohaus, C114) daily, accurate to $0.1 \mathrm{mg}$. The amount of sucrose consumption was recorded as the difference in weight of sucrose between two consecutive days, this was then divided by the number of workers still alive that day to obtain daily consumption per bee. Loss of moisture in sugar, if any, was corrected by measuring the moisture content in the sugar measured sugar content with solid sugar solution with an Abbe refractometer (WYA-2W, INESA Scientific Instrument Co., Ltd., China) at $40{ }^{\circ} \mathrm{C}$ each day in a sugar ball not reachable by bees.

The experiment was replicated three times, each time with a different colony from each 
species of honey bees (three cages per species and colony).

\subsection{Lab study: worker longevity with sugar and pollen}

Powdered bee pollen from lotus (Nelumbo nucifera) was mixed with $50 \%$ sucrose syrup in the ratio of 2: $1(w: w)$ and soaked for $24 \mathrm{~h}$. Caged bees were prepared the same as the last experiment. Water and 50\% $(w: w)$ sucrose syrup, filled in two $15 \mathrm{~mL}$ glass feeding bottles, were provided via two holes on the top of each cage. Bee pollen was supplied with a cap $10 \mathrm{~mm} \times 30 \mathrm{~mm}$ (height $\times$ inner diameter). All water, sucrose syrup, and bee pollen were replaced daily. Dead workers were recorded and removed from each cage daily.

The experiment was replicated three times, each time with a different colony from each species of honey bees (three cages per species and colony).

\subsection{Field study: survival, biomass, and foraging performance of $A c$ and $A m$ workers in mixed species colonies}

Mixed species colonies were each established by keeping one frame of mature brood from each species and an Am queen in the incubator at $34.5{ }^{\circ} \mathrm{C}$ and $75 \% \mathrm{RH}$ for 5 days. The workers were transferred into an observation hive $(47 \mathrm{~cm}$ length, $5 \mathrm{~cm}$ width, and $51 \mathrm{~cm}$ height). An empty frame and one frame with half honey and one third pollen were maintained in the observation hive. The mixed species colony contained equal number $(\sim 3000)$ of Ac and Am workers counted via photos. In addition, the mixture of pollen and sucrose syrup in the ratio of $2: 1(w: w, 50 \mathrm{~g})$ was provided on the top of frame via a hole in cover (diameter $2 \mathrm{~cm}$ ). Sucrose syrup was also supplied with a feeder $(15 \mathrm{~mL}$ glass bottles with plastic cap) inserted into another feeding holes on the top cover. The mixed species colony was managed for 20-25 days to reach a normal age demography before marked focal bees were introduced. Occasional fighting between Ac and Am workers was controlled by spraying sucrose syrup (sucrose/olive oil/water $=5: 1: 4(w: w: w)$ (Extra virgin grade, Terra Creta S.A.)) in colony.
Newly merged bees (99/colony/species) were tagged with numbered and colored tags (Bee Research Institute at Dol, Czech Republic) and then introduced into the mixed species colony. In addition, newly emerged workers of Ac were also introduced periodically (about 500 bees, once in every 2 weeks) to balance with the Am workers produced by the Am queen. Sampling grids, 1 to 32 on one side, and 33 to 64 on the other side, were constructed on the window wall of observation hive. The census was done starting from first grid on the top left, and toward right and lower grids sequentially in a black room at 21:00 (Time Zone +8 ). The numbers of bees for each species still alive in the colony were censored every 3 to 5 days at the same time. If a tagged bee was absent in all dates after one certain date, this date was assumed to be its last day alive. The experiment was also replicated three times, each time with a different mixed species colonies (three mixed species colonies).

The biomass of departing exiting workers was measured with a precision electronic balance (Ohaus, C114). Exiting workers were caught with a pair of soft forceps (Bioquip, USA) and individually put into Eppendorf tubes $(1.5 \mathrm{~mL})$. The weight difference between an Eppendorf tube only and the tube with a labeled worker was measured and considered to be the weight of a labeled worker. The weight of a labeled worker minus their tag weight is the biomass of a worker. The biomass of different aged (days 15 to 31) Ac and Am workers was determined. Weight of workers of each age $(N=10)$ were determined in three different mixed species colonies.

Similarly, the foraging frequency and forager number of Am and Ac workers were compared when the tagged bees were 14 to 25 days old. A special entrance (S Figure 1) was designed to separate incoming and outgoing bees, so that the time and direction of their trip could be recorded. The outgoing and incoming bees were recorded 7 to $10 \mathrm{am}$ in the morning and 1 to $4 \mathrm{pm}$ in the afternoon (UTC+08:00). To remove a possible effect of time of observation, the time of observation was rotated evenly among the three colonies (e.g., starting at 7, 8, and 9 for colonies A, B, and C for day 1 , then 9,10 , and 8 for day 2 , and 10,8 , and 9 for day 3 , etc.). The number of foragers was 


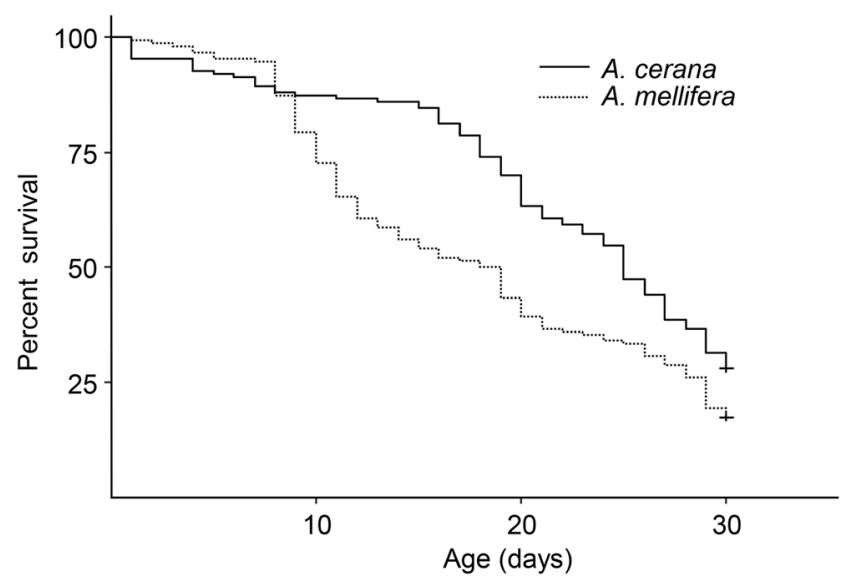

Figure 1 Survival of A. cerana and A. mellifera workers fed with only sucrose in laboratory $\left(34.5{ }^{\circ} \mathrm{C}, 50 \% \mathrm{RH}\right)$ ( $N=50$ per group, bees caged by species, replicated over three colonies). The difference in survival was highly significant (log rank test, $P<0.0001$ ) between the two species.

normalized to the number of alive bees. Workers were regarded as foragers when their duration of trip was longer than 5.5 min (Capaldi et al. 2000).

\subsection{Data analysis}

The results are reported as means \pm standard errors ( \pm SE). Normality test was performed using StatView Version 5.0.1 for Windows (SAS Institute Inc. 1992-1998, NC, USA) with the K-S Normality Test, and all data conformed to normal distribution. Biomasses of different aged foragers were compared by ANOVA. Sugar consumption and foraging frequency during different ages were treated as repeated measures ANOVA using StatView software. Survival analysis of both species of honey bees was carried out using SPSS version 19.0. with log rank tests.

\section{RESULTS}

\subsection{Lab study: worker longevity with sugar only and sugar consumption}

Survival of Ac workers fed with sucrose only was significantly higher than that of Am workers (Figure 1; $\log \operatorname{rank} X^{2}=11.5, \mathrm{df}=1 ; P<0.0001$ ).

The daily sucrose consumption was higher for Am workers than that of Ac workers throughout the lifespan (1-day-old to 30-day-old) (Figure 2; repeated measures ANOVA, $F_{1,59}=601.02$, $P<0.0001)$. There were significant changes in sugar consumption among different ages $\left(F_{29}\right.$, ${ }_{87}=1.78, P=0.03$ ) for either species. The average daily sucrose consumption of Am workers $(11.73 \pm 0.45 \mathrm{mg})$ was almost three times that for Ac workers $(3.76 \pm 0.20 \mathrm{mg})$. In addition, the variance of sugar consumption was also much higher for Am workers (16.61) than that of Ac workers (2.95); the difference between the two variances was highly significant $\left(F_{90,90}=5.64\right.$, $P<0.001)$.

\subsection{Lab study: worker longevity with sugar and pollen}

Survival of Am workers with sucrose and bee pollen in the laboratory was significantly higher than that of Ac workers (Figure $3 ; X^{2}=159$, df = $1 ; P<0.0001)$.

\subsection{Field study: survival, biomass, and foraging performance of Ac and Am workers in mixed species colonies}

In mixed species colonies, survival of Ac workers was significantly better than that of Am workers (Figure $4 ; X^{2}=10.9, \mathrm{df}=1 ; P<0.0001$ ). 


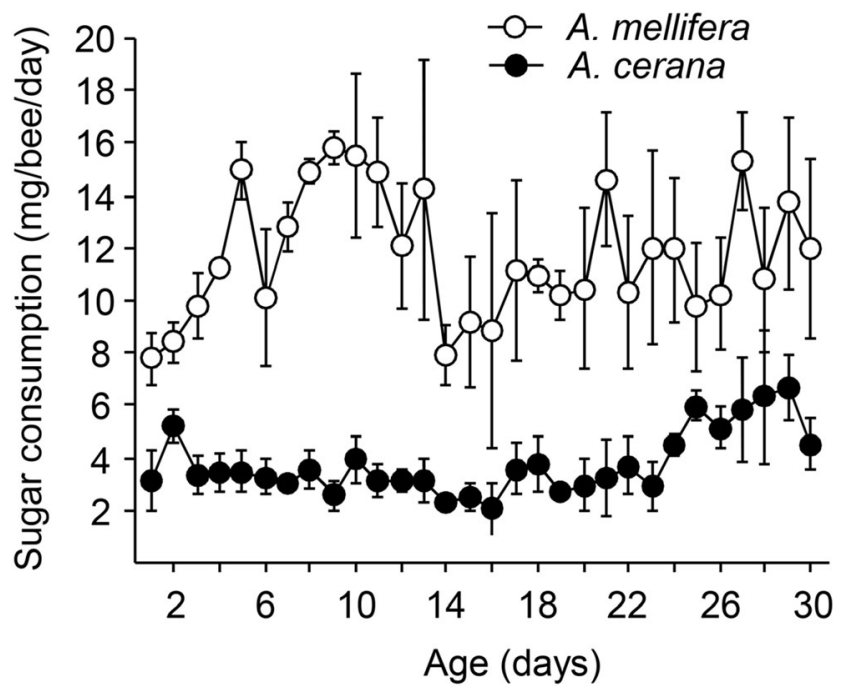

Figure 2 Daily mean (+SE) sucrose consumption of different aged A. cerana and A. mellifera workers in laboratory $\left(34.5^{\circ} \mathrm{C}, 50 \% \mathrm{RH}\right)(N=50$ per cage, three colonies). This was calculated from total sugar consumed divided by the number of live workers in each cage on each day. The difference in daily sucrose consumption was highly significant (ANOVA with repeated measures, $P<0.0001$ ) between the two species. In addition, the variance of $A$. mellifera was significantly higher than that of $A$. cerana ( $F$ test, $P<0.001$ ).

Biomasses between Ac and Am were significantly different (Figure 5; $F_{1,270}=67.69$, $P<0.0001)$. The body masses of Ac and Am changed significantly with age $\left(F_{4,270}=73.91\right.$, $P<0.0001)$. There were no significant differences in worker biomass for both species among the three different mixed species colonies $\left(F_{2}\right.$, $270=0.29, P=0.75)$. There were no significant interactions between species and colonies $\left(F_{2}\right.$, $270=0.47, P=0.62)$, age and colonies $\left(F_{8,270}=\right.$ $0.21, P=0.99)$, and species, age, and colonies $\left(F_{8,270}=0.43, P=0.90\right)$ with an exception of species and age $\left(F_{4,270}=15.36 ; P<0.0001\right)$ in worker biomass.

Number of foraging trips (all foragers together) per $2 \mathrm{~h}$ was significantly higher for Ac than Am

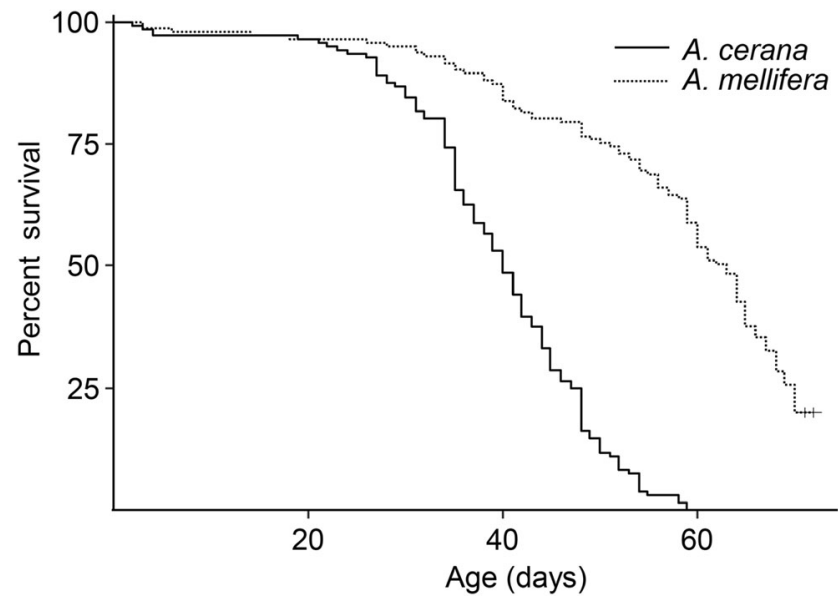

Figure 3 Survival of A. cerana and A. mellifera workers fed with sucrose and bee pollen in laboratory $\left(34.5^{\circ} \mathrm{C}\right.$, $50 \% \mathrm{RH})(N=50$ per group, bees caged by species, three colonies). The difference in survival was highly significant (log rank test, $P<0.0001$ ) between the two species. 


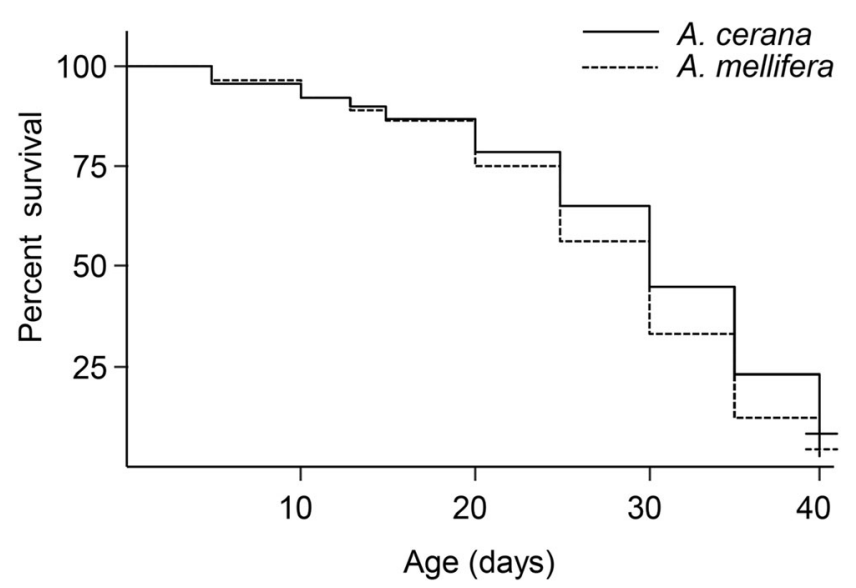

Figure 4 Survival of A. cerana and A. mellifera workers in the mixed species colony ( $N=99$ bees in the same colony per species, averaged over three colonies). The difference in survival was highly significant (log rank test, $P<0.0001)$ between the two species.

(Figure 6a; repeated measures ANOVA, $F_{1,24}=$ $30.22, P<0.0001)$. There was also a significant age effect on number of foraging trips $\left(F_{11,24}=\right.$ 21.23, $P<0.0001)$ in both species. There were significant interactions between species and worker age for the number of foraging trips $\left(F_{11,34}=\right.$ 2.7, $P=0.02$ ).

Number of foragers were significantly higher for Ac workers than that of Am
(Figure $6 \mathrm{~b} ; F_{1,24}=17.87, P=0.0003$ ). Forager numbers changed significantly as age changed $\left(F_{11,24}=23.59, P<0.0001\right)$. There were also significant interactions between species and worker age for forager number $\left(F_{11}\right.$, $34=2.66, P=0.022)$. The average number of foraging trips per forager per time period of Ac was also significantly higher than $\operatorname{Am}\left(F_{11}\right.$, $\left.{ }_{24}=3.186, P=0.0085\right)$.

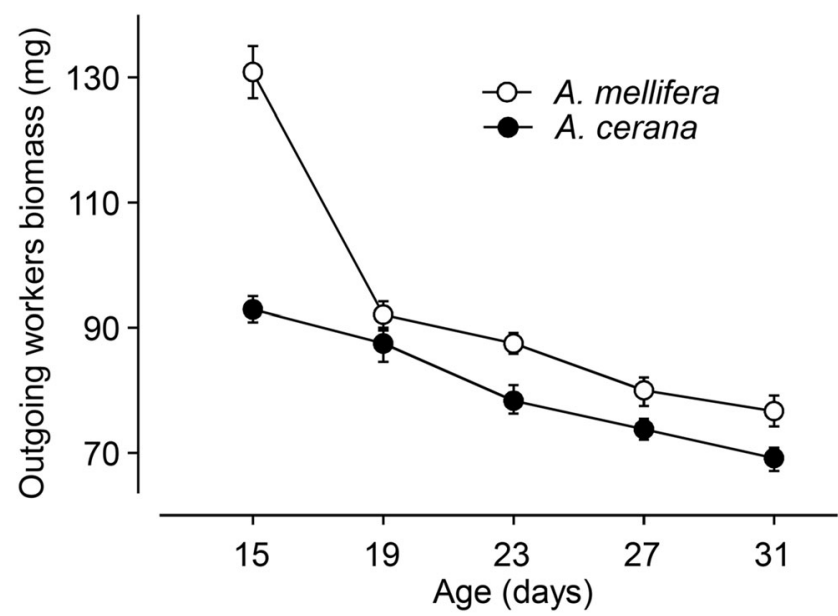

Figure 5 Mean $( \pm$ SE) weight of exiting workers of A. cerana and A. mellifera $(N=10$ bees per day per species). The difference in biomass was highly significant (ANOVA with repeated measures, $P<0.0001$ ) between the two species. There were also significant age-related changes $(P<0.0001)$ in both species. 

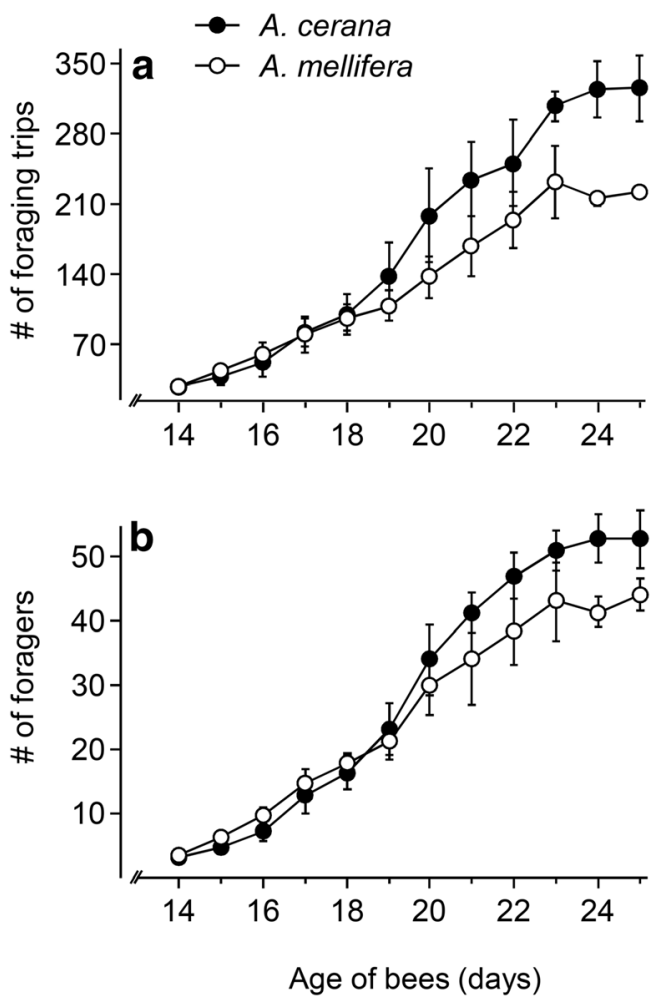

Figure 6 Foraging performance of $A$. cerana and A. mellifera workers in mixed species colony $(N=99$ per species, averaged over three colonies). The differences were highly significant between the two species, for the number of foraging trips per $2 \mathrm{~h}$ (ANOVA with repeated measures, $P<0.0001)$ and number of foragers $(P=0.0004)$. The number of foraging trips (duration longer than $5.5 \mathrm{~min}$ ) of tagged workers (a) was based on observation in $2 \mathrm{~h}$. Forager numbers (b) were also determined in the same period.

\section{DISCUSSION}

The main findings of this study are that Ac workers have longer longevity than Am workers if longevity is measured in caged bees without pollen or in mixed species colonies; Ac workers have lower sugar consumption than Am; and finally Ac workers have higher proportion of foragers and make more foraging trips. These results suggest new mechanisms that Ac can perform better than Am at the colony level, when nectar and/or pollen resources are scarce.

The longevity of Ac and Am differed under different conditions. For example, when provided with pollen, Am survived much longer than Ac (Figure 3), even though Ac survived longer than Am when no pollen was provided, or measured inside the mixed species colonies. It is possible that Nelumbo pollen is highly nutritious for Am but not for Ac, thus accounting for the reversal of our longevity data of the two species when provided with pollen. Our results showing that both species increased their longevity when provided with pollen (Figure 1 and Figure 3) are consistent with previous studies showing that in general pollen increases worker longevity (Schmidt et al. 1987; Schmidt et al. 1995). The survival results of both species in the same mixed species colonies might be most reliable, because there all conditions for both species remained the same; and it has been known both conditions outside and inside colonies can affect honey bee survival (Woyciechowski and Kozlowski 1998). The slightly longer lifespan of Ac workers would help Ac colonies build up faster, when all other conditions are equal.

The second advantage of Ac is lower sugar consumption. Ac consumed $3.76 \mathrm{mg}$ sucrose per worker per day while Am needed $11.73 \mathrm{mg}$ in lab condition $\left(34.5^{\circ} \mathrm{C}\right.$ and $\left.50 \% \mathrm{RH}\right)$ (Figure 2). This is very close to the $11 \mathrm{mg}$ sugar consumption per day per worker reported by Huang et al. (1998). Obviously, colonies with less sugar consumption should have more honey left when their worker numbers and honey stores started at the same levels. The lower sugar consumption of Ac might be partly due to their smaller sizes. Larger biomass animals have higher resting metabolic rates (Speakman 2005; Chown et al. 2007). This is also true for honey bees, with Am showing higher metabolic rates than Ac both during foraging $(1.21 \pm 0.06$ vs $0.73 \pm 0.16 \mathrm{~J} /$ bee/day, for Am and Ac, respectively) and during rest (0.027 vs $0.011 \mathrm{~J} /$ bee/day) (Abrol 2007). However, the differences in metabolism were only about two times in that study and our data here show a threefold difference in sugar consumption. It is possible that this is due to a combined effect of differences in body sizes and metabolic rates. Am workers also show a much higher variation for their daily sugar consumption. This variation could also cause starvation more frequently if food supply is constant.

There have been a few studies showing that foragers in Am are much lighter than in-hive workers, with foragers weighing about $40 \%$ less 
compared to younger bees (Harrison 1986). Our data here show that Ac workers have the same pattern: that foragers lose about $20.2 \%$ of weight compared to 15-day-old workers (Figure 5). The forager weight of Am was $81.44 \pm 1.32 \mathrm{mg}$ and Ac was $73.75 \pm 1.21 \mathrm{mg}$ (Figure 5, for bees 23 days or older). These results for Am are similar to those of Harrison and Hall (1993) and Feuerbacher et al. (2003). Our biomass data of Am and Ac foragers are different from another study in China (93.3 \pm $1.7 \mathrm{mg}$ for Am and 69.3 $\pm 1.0 \mathrm{mg}$ for Ac) (Tan et al. 2012a) but show the same trend. The differences of workers' biomass between our data and previous report may due to the genetics (Harrison and Hall 1993)) or foragers' age (Figure 5).

Another advantage of Ac is that they have a higher proportion of foragers and their foragers make more foraging trips. Ac had 20\% more foragers with the same group size $(n=99)$ (Figure 6a) and foragers made $25 \%$ more foraging trips (Figure 6b). The higher numbers of foraging trips of Ac could be due to their shorter foraging distance (Koetz 2013; He et al. 2013) or its better learning and memory for color and grating patterns (Qin et al. 2012), or both. With more foraging trips, Ac will increase the amount of nectar brought into the colonies when all other conditions are equal. However, Am foragers carry heavier nectar loads than Ac $(51.0 \pm 1.9$ vs $31.3 \pm 1.2 \mathrm{mg}$ ) (Tan et al. 2012a), while the two species of foragers show no different sugar concentrations in collected nectar (Yang et al. 2013). The longer foraging life, more foragers and more foraging trips of Ac will increase the amount of nectar brought into colonies.

Mixed species colonies were used to compare different honey bee behaviors in this study. Mixed species colonies with the same numbers of bees in two species, Am and Ac, have been used previously in many studies for different purposes, such as worker reproductive physiology (Tan et al. 2009a), brood recognition (Tan et al. 2009b), comb building (Yang et al. 2010a), retinue behavior (Yang et al. 2010b), thermoregulation (Yang et al. 2010c), defensive behavior against wasps (Tan et al. 2012b), communication using the dance language (Tan et al. 2008), and proboscis extension response to sugar solutions (Yang et al. 2013). In some of these studies, behaviors in mixed species colonies and in their own colonies were compared. The behaviors of worker reproductive physiology (Tan et al. 2009a), thermoregulation (Yang et al. 2010c), defense against wasp (Tan et al. 2012b), brood recognition ability (Tan et al. 2009b), and proboscis extension response to sugar syrup (Yang et al. 2013) in mixed species colonies were consistent with behaviors in their own colonies. These results suggest that mixed species colonies are useful tools to compare the differences between behaviors of different species of honey bees. But there are differences in comb building (Yang et al. 2010a) and retinue behaviors (Yang et al. 2010b) when studied in mixed species colonies compared to when in their own colonies. Mixed race colonies with European and Africanized bees were also used for foraging performance (Winston and Katz 1982). There are no differences between duration of first flight and total flight duration in conspecific colonies and those in mixed species colonies; but age of first flight, age of first foraging, and flights per hour are different in these two types of colonies. Winston and Katz (1982) conjectured that these differences were due to different stimulus thresholds in the two races of honey bees, and the stimulus levels are also different in the colonies of these two bees. Because of this, Africanized bees foraged earlier than European bees when they are in their own colonies, but Africanized bees foraged later than European bees when they were co-fostered in the same colony. Thus, some behaviors can be complex and might have to be studied under both conditions.

We used three mixed species colonies, all with Am queens but no Ac queen, because mixed species colonies headed by Ac queen are too difficult to obtain. Queen mandibular gland pheromone (QMP) can affect foraging behavior, notably by delaying the foraging age and decreasing the number of returning foragers at a natural dose (Pankiw et al. 1998). In present study, Ac workers receive more QMP in mixed species colonies hosted by Am queen than in Ac's own colonies because of Am queens having 45\% more QMP than Ac queen (Yang et al. 2010b). We however believe that the higher foraging frequency and more foragers in Ac than those in Am is not due to the higher amount of QMP experienced by Ac in mixed species colonies. Indeed, in Am colony, higher amount of QMP enhances pollen foraging (Higo et al. 1992) and increases nectar foragers and nectar foraging activity 
at the third day after treatment (Pettis et al. 1995) but has no effect on total foragers or foraging activity. These studies however used Am and the data are lacking in how do Ac workers respond to different levels of QMP. Further studies are needed to determine what factors regulate foraging effort and frequency in Ac workers.

\section{CONCLUSION}

In conclusion, Apis cerana workers make more foraging trips, have a higher forager proportion, consume less sugar, and survive longer compared to Apis mellifera workers under the same conditions. These features may contribute to the ability of Apis cerana to store more honey during winter and/or in resource poor areas such as mountainous areas.

\section{ACKNOWLEDGMENTS}

This study was supported by College Students Innovation Project from Fujian Agriculture and Forestry University (201510389202).

\section{AUTHOR CONTRIBUTIONS}

WY and ZYH designed and conceived this research, analyzed the data, and wrote the manuscript; SP and CZ performed experiments; XM and $\mathrm{ZW}$ provided experimental materials and advised on the experiments. All authors read and approved the final manuscript.

\section{COMPLIANCE WITH ETHICAL STANDARDS}

Conflict of interest The authors declare that they have no conflict of interest.

Longévité, consommation alimentaire et performance de butinage d'Apis cerana et d'Apis mellifera dans des colonies mixtes

Apis cerana / Apis mellifera / consommation de sucre / butinage / survie
Lebensdauer, futteraufnahme und Sammelleistung von Apis cerana and Apis mellifera in gemischten Bienenvölkern

Apis cerana / Apis mellifera / Zuckeraufnahme / Sammelaktivität / Überleben

Publisher's note Springer Nature remains neutral with regard to jurisdictional claims in published maps and institutional affiliations.

\section{REFERENCES}

Abrol, D.P. (2007) Differences in sugar metabolism between the honey bees Apis mellifera and Apis cerana impact floral attractiveness. J. Apicult. Res. https://doi. org/10.1080/00218839.2007.11101390.

Beekman, M. and Ratnieks, F.L.W. (2000). Long-range foraging by the honey-bee, Apis mellifera L. Funct. Ecol. 14:490-496.

Capaldi, E.A., Smith, A.D., Osborne, J.L., Fahrbach, S.E., Farris, S.M. et al. (2000) Ontogeny of orientation flight in the honeybee revealed by harmonic radar. Nature, 403: 537-540.

Chandel, Y.S., Kumar, A. and Srivastva, S. (2000) Comparative performance of Apis mellifera L. vis a vis Apis cerana Fab. on toria (Brassica campestris var Toria ) in mid-hill zone of Himachal Pradesh, India. Indian J. Agric. Res. 34, 264-267.

Chown, S.L., Marais, E., Terblanche, J.S., Klok, C.J., Lighton, J.R.B. and Blackburn, T.M. (2007) Scaling of insect metabolic rate is inconsistent with the nutrient supply network model. Func. Ecol. https://doi. org/10.1111/j.1365-2435.2007.01245.x.

FAO (2016) Food and Agriculture Organization Corporate Statistical Database (FAOSTAT). Food and Agricultural Organization of the United Nations [online] URL: http://faostat.fao.org/beta/en/\#data/QA (accessed on 17 NOV. 2016).

Feuerbacher, E., Fewell, J.H., Roberts, S.P., Smith, E.F. and Harrison, J.F. (2003) Effects of load type (pollen or nectar) and load mass on hovering metabolic rate and mechanical power output in the honey bee Apis mellifera. J. Exp. Biol. https://doi.org/10.1242 /jeb.00347.

Gupta, J.K., Mishra, R.C. and Kumar, J. (1984) Plectranthus as forage for Apis cerana indica F. and Apis mellifera L.. Apidologie, https://doi.org/10.1007 /BF01087038.

Harrison, J.M. (1986) Caste-specific changes in honeybee flight capacity. Physiological Zoology.https://doi. org/10.1086/physzool.59.2.30156031.

Harrison, J.F. and Hall, H.G. (1993) African-European honeybee hybrids have low nonintermediate metabolic capacities. Nature, 363: 258-260. 
He, X., Wang, W., Qin, Q., Zeng, Z., Zhang, S. and Barron, A.B. (2013) Assessment of flight activity and homing ability in Asian and European honey bee species, Apis cerana and Apis mellifera, measured with radio frequency tags. Apidologie, https://doi.org/10.1007 /s13592-012-0156-7.

Higo, H.A., Colley, S.J., Winston, M.L. and Slessor, K.N. (1992) Effects of honey bee (Apis mellifera L.) queen mandibular gland pheromone on foraging and brood rearing. The Canadian Entomologist, https://doi. org/10.4039/Ent124409-2

Huang, Z.Y., Plettner, E. and Robinson, G.E. (1998) Effects of social environment and worker mandibular glands on endocrine-mediated behavioral development in honey bees. J. Comp. Physiol. A 183, 143-152.

Koetz, A.H. (2013) Ecology, behaviour and control of Apis cerana with a focus on relevance to the Australian incursion. Insects, https://doi.org/10.3390 /insects4040558.

Liu, Y.W. (1964) Relationship of morphological characteristics and productivity of Apis cerana. Apiculture of China 5, 133-136.

Liu, Z., Chen, C., Niu, Q. Qi, W., Yuan, C., et al., (2016) Survey results of honey bee (Apis mellifera) colony losses in China (2010-2013). J. Apicult. Res. https://doi.org/10.1080/00218839.2016.1193375.

Ma, D. and Huang W. (1993) Chinese Agricultural Encyclopedia - Apiculture Volume, Beijing.

Pankiw, T, Huang, Z.Y., Winston, M.L. and Robinson, G.E. (1998) Queen mandibular gland pheromone influences worker honey bee (Apis mellifera L.) foraging ontogeny and juvenile hormone titers. J. Insect. Physiol. https://doi.org/10.1016/S0022-1910(98)00040-7.

Partap, U., Shukla, A. N. and Verma, L.R. (2000) Comparative foraging behaviour of Apis cerana and Apis mellifera in pollinating peach and plum flowers in Kathmandu Valley Nepal. Proceedings of the 4th Asian apicultural association conference, Kathman$d u$. Science Publisher, Nepal. pp. 193-198.

Pettis, J.S, Winston, M. and Slessor, K.N. (1995) Behavior of queen and worker honey bees (Hymenoptera, Apidae) in response to exogenous queen mandibular gland pheromone. Ann. Entomol. Soc. Am. https://doi.org/10.1093/aesa/88.4.580.

Qin, Q., He, X., Tian, L., Zhang, S. and Zeng, Z. (2012) Comparison of learning and memory of Apis cerana and Apis mellifera. J. Comp. Physiol. A https://doi. org/10.1007/s00359-012-0747-9.

Schmidt, J.O., Thoenes, S.C. and Levin, M.D. (1987) Survival of honey bees, Apis mellifera (Hymenoptera: Apidae) fed various pollen sources. Ann. Entomol. Soc. Am. https://doi.org/10.1093/aesa/80.2.176.

Schmidt, L.S., Schmidt, J.O., Rao, H., Wang, W. and Xu, L. (1995) Feeding preference and survival of young worker honey bees (hymenoptera: apidae) fed rape, sesame and sunflower pollen. J. Econ. Entomol. 88, 1591-1595.

Speakman, J.R. (2005) Body size, energy metabolism and lifespan. J. Exp. Biol. https://doi.org/10.1242 /jeb.01556.
Tan, K., Yang, M.X., Radloff, S.E., Hepburn, H.R., Zhang, Z.Y., Luo, L.J. and Li, H. (2008) Dancing to different tunes: heterospecific deciphering of the honeybee waggle dance. Naturwissenschaften, https://doi. org/10.4039/Ent124409-2.

Tan, K., Yang, M.X., Radloff, S., Pirk, C.W., Crewe, R.M., et al. (2009a) Worker reproduction in mixed-species colonies of honey bees. Behav. Ecol. https://doi. org/10.1093/beheco/arp103.

Tan, K., Yang, M.X., Radloff, S.E., Yu, Y., Pirk, C.W. and Hepburn, H.R. (2009b) Intra-and interspecific brood recognition in pure and mixed-species honeybee colonies, Apis cerana and A. mellifera. Apidologie, https://doi.org/10.1051/apido/2009003.

Tan, K., Yang, S., Wang, Z., Radloff, S.E. and Oldroyd, B.P. (2012a) Differences in foraging and broodnest temperature in the honey bees Apis cerana and A. mellifera. Apidologie, https://doi.org/10.1007 /s13592-012-0136-y.

Tan, K., Yang, M.X., Wang, Z.W., Li, H., Zhang, Z.Y. et al. (2012b) Cooperative wasp-killing by mixed-species colonies of honeybees, Apis cerana and Apis mellifera. Apidologie, https://doi.org/10.1007 /s13592-011-0098-5.

Wang, Z. and Tan, K. (2014) Comparative analysis of olfactory learning of Apis cerana and Apis mellifera. Apidologie, https://doi.org/10.1007/s13592-013-0228-3.

Winston, M.L. and Katz, S.J. (1982) Foraging differences between cross-fostered honeybee workers (Apis mellifera) of European and Africanized races. Behav. Ecol. Sociobiol. 10: 125-129.

Woyciechowski, M. and Kozlowski, J. (1998) Division of labor by division of risk according to worker life expectancy in the honey bee (Apis mellifera L.). Apidologie, https://doi.org/10.1051/apido:19980111.

Yang, G.H. (2005) Harm of introducing the western honeybee Apis mellifera L. to the Chinese honeybee Apis cerana $\mathrm{F}$. and its ecological impact. Acta Entornologica Sinica, 48, 401-406.

Yang, M.X., Tan, K., Radloff, S.E., Phiancharoen, M. and Hepburn, H.R. (2010a). Comb construction in mixedspecies colonies of honeybees, Apis cerana and Apis mellifera. J. Exp. Biol. https://doi.org/10.1242 /jeb.035626.

Yang, M.X., Tan, K., Radloff, S.E., Pirk, C.W. and Hepburn, H.R. (2010b). Hetero-specific queen retinue behavior of worker bees in mixed-species colonies of Apis cerana and Apis mellifera. Apidologie, https://doi.org/10.1051/apido/2009047.

Yang, M.X., Wang, Z.W., Li, H., Zhang, Z. Y., Tan, K., Radloff, S. E., Hepburn, H. R. (2010c) Thermoregulation in mixed-species colonies of honeybees (Apis cerana and Apis mellifera). J. Insect. Physiol. https://doi.org/10.1016/j.jinsphys.2009.12.011.

Yang, W., Kuang, H., Wang, S., Wang, J., Liu, W. et al . (2013) Comparative Sucrose Responsiveness in Apis mellifera and A. cerana Foragers. PLoS ONE, 8: e79026. 